\title{
Design and Optimization of Mefloquine Hydrochloride Microparticles for Bitter Taste Masking
}

\author{
Punit P. Shah, ${ }^{1,2}$ Rajashree C. Mashru, ${ }^{1}$ Yogesh M. Rane, ${ }^{1}$ and Arti Thakkar ${ }^{1}$
}

Received 24 July 2008; accepted 19 January 2008; published online 20 February 2008

\begin{abstract}
The objective of the present investigation was to reduce the bitterness with improved dissolution, in acidic medium ( $\mathrm{pH}$ 1.2), of mefloquine hydrochloride (MFL). Microparticles were prepared by coacervation method using Eudragit E (EE) as polymer and sodium hydroxide as precipitant. A $3^{2}$ full factorial design was used for optimization wherein the drug concentration (A) and polymer concentration (B) were selected as independent variables and the bitterness score, particle size and dissolution at various $\mathrm{pH}$ were selected as the dependent variables. The desirability function approach has been employed in order to find the best compromise between the different experimental responses. The model is further cross validated for bias. The optimized microparticles were characterized by FT-IR, DSC, XRPD and SEM. Bitterness score was evaluated by human gustatory sensation test. Multiple linear regression analysis revealed that the reduced bitterness of MFL can be obtained by controlling the dissolution of microparticles at $\mathrm{pH} 6.8$ and increasing the EE concentration. The increase in polymer concentration leads to reduction in dissolution of microparticles at $\mathrm{pH}>5$ due to its insolubility. However the dissolution studies at $\mathrm{pH} 1.2$ demonstrated enhanced dissolution of MFL from microparticles might be due to the high porosity of the microparticles, hydrophilic nature of the EE, and improved wettability, provided by the dissolved EE. The bitterness score of microparticles was decreased to zero compared to $3+$ of pure ARM. In conclusion the bitterness of MFL was reduced with improved dissolution at acidic $\mathrm{pH}$.
\end{abstract}

KEY WORDS: bitterness; eudragit; full factorial design; mefloquine $\mathrm{HCl}$; microparticles.

\section{INTRODUCTION}

In recent years, the importance of patient compliance, not only in drug efficacy per se, but also in overall economics of healthcare, has been increasingly recognized. Efforts to improve patient compliance have included attempts to improve the palatability of orally administered pharmaceutical agents especially for children and elderly $(1,2)$. In particular, a bitter taste is known to decrease patient compliance, and thus reduce effective pharmacotherapy.

In the present study, the possibility of masking the bitterness of mefloquine hydrochloride (MFL), a drug used as a treatment for malaria, was investigated. MFL has an extremely unpleasant bitter taste due to presence of quinine moiety (3). As this is likely to give rise to non-compliance when administered orally, it would be a considerable advantage to be able to mask the bitterness of oral formulations containing MFL.

In order to achieve an acceptable palatability, the addition of flavors or sweeteners is limited and may not be efficient enough to mask the bitter taste of drugs, requiring the use of

\footnotetext{
${ }^{1}$ Center of Relevance and Excellence in NDDS, Pharmacy Department, The M. S. University of Baroda, G H Patel building, Donor's Plaza, Fatehgunj, Vadodara, Gujarat, India, 390002.

${ }^{2}$ To whom correspondence should be addressed. (e-mail: punit pshah@gmail.com)
}

technological processes (4-6). A number of taste-masking approaches have been described in the literature, including the use of cyclodextrin (7), ion exchange resin $(8,9)$, film coating (10), viscosity modification (11) and melt granulation (12). Among the various techniques, microencapsulation has often proved to be the most successful in reducing the bitterness of bitter active pharmaceutical ingredients because it is simple, economic and advantageous (13).

The objective of present investigation was to completely mask the bitter taste of MFL by encapsulation in microparticles, while allowing the complete release of MFL under the acidic conditions of stomach $(\mathrm{pH}$ 1.2). The $\mathrm{pH}$ inside the oral cavity has been reported to be about 6.8 (14). A $3^{2}$ full factorial design was used for optimization wherein the drug concentration (A) and polymer concentration (B) were selected as independent variables and the bitterness, particle size and dissolution at various $\mathrm{pH}$ were selected as the dependent variable.

Eudragit E, an acid-soluble polymer, was selected for the encapsulation of MFL. It has been reported that this polymer is a cationic copolymer based on dimethyl aminoethyl methacrylate and neutral methacrylic esters soluble up to $\mathrm{pH} 5$; however it is swellable and permeable above $\mathrm{pH} 5$ $(15,16)$. Sodium hydroxide was used as precipitating agent. This alternative microparticles preparation method can be applied, replacing the complicated and sophisticated quasi emulsion solvent diffusion (17), spray drying (16), solvent 
Table I. Variables in $3^{2}$ Full Factorial Design

\begin{tabular}{|c|c|c|c|}
\hline \multirow[b]{2}{*}{ Variables } & \multirow[b]{2}{*}{ Characteristic } & \multicolumn{2}{|c|}{ Actual Values } \\
\hline & & Drug Conc. $(A$ in $\mathrm{g})$ & Polymer Conc. $(B \text { in } \mathrm{mL})^{a}$ \\
\hline \multicolumn{4}{|c|}{ Independent variables } \\
\hline A & Drug concentration & & \\
\hline $\mathrm{B}$ & Polymer concentration & & \\
\hline \multicolumn{4}{|c|}{ Dependent variables } \\
\hline Y1 & Particle size & & \\
\hline $\mathrm{Y} 2$ & Dissolution at $\mathrm{pH} 1.2$ & & \\
\hline Y3 & Dissolution at $\mathrm{pH} 6.8$ & & \\
\hline Y4 & Bitterness score & & \\
\hline \multicolumn{4}{|l|}{ Coded values } \\
\hline-1 & & 0.3 & 10 \\
\hline 0 & & 0.5 & 30 \\
\hline 1 & & 0.7 & 50 \\
\hline
\end{tabular}

${ }^{a} \mathrm{~mL}$ of $1 \% w / v$ EE solution, prepared in $1 \% v / v$ acetic acid

evaporation (18), solid dispersion by supercritical fluids (19), co evaporates (20) and non-aq. granulation (15) used in prior formulations. Further the present method avoids use of special instrument, hazardous organic solvent and is easy to scale up.

\section{MATERIALS AND METHODS}

\section{Materials}

Mefloquine hydrochloride (Batch no. 031209) was a gift from Ajanta Pharma Ltd, (Mumbai, India). Eudragit E (EE) (Batch no. G041131159) was a gift from Degussa India Pvt. Ltd., (Mumbai, India). Methanol was purchased from Qualigens Fine Chemicals (Mumbai, India) and was used as received. Sodium hydroxide, hydrochloric acid, potassium dihydrogen phosphate, and acetic acid were purchased from S. D. Fine-Chem Ltd., (Mumbai, India) and were used as received.

\section{Preparation of Microparticles}

Microparticles were prepared by coacervation phase separation method. A concentrated solution of $\mathrm{EE}(\sim 1 \% \mathrm{w} / \mathrm{v})$ was prepared in $1 \% v / v$ acetic acid. The required quantity of the MFL ( $0.6 \mathrm{~g}$ in $50 \mathrm{~mL}$ of final EE solution) was mixed for $5 \mathrm{~min}$. Ten milliliters of $10 \% \mathrm{w} / \mathrm{v}$ sodium hydroxide solution was introduced into a $10-\mathrm{ml}$ of glass syringe with a $18 \mathrm{G} \times 1 / 2$ " flat-cut hypodermic needle. The droplets were amputated at a flow rate of $3 \mathrm{ml} / \mathrm{min}$ into EE solution. The resulting microparticles were allowed to harden for $60 \mathrm{~min}$ under gentle stirring at $400 \mathrm{rpm}$ (Remi Equipments Pvt. Ltd., Mumbai, India) with small magnetic bar. Actual values of independent factors are listed in Table I. Different concentrations of MFL and EE were used, according to the experimental runs, mentioned in Table II. The microparticles were collected, decanted, washed with deionized water and dried to a constant weight in oven (Shree Kailash Industries, Baroda, India) at $80{ }^{\circ} \mathrm{C}$ for $24 \mathrm{~h}$, and then stored in the desiccator until use. The percentage yield was calculated as:

$$
\text { Percent yield }=\frac{\text { Calculated yield }}{\text { Theoretical yield }} \times 100
$$

\section{Experimental Design}

A $3^{2}$ full factorial design was employed to systematically study the joint influence of the effect of independent variables

Table II. Presentation of Experiments with Coded Values for Factor Levels for $3^{2}$ Full Factorial Design with their Percent Yield and Incorporation Efficacy of Microparticles

Factors and Factor Levels

\begin{tabular}{ccccc}
\cline { 2 - 3 } Formulation no. & Drug Conc. (A) & Polymer Conc. (B) & Percent Yield $\pm \mathrm{SD}^{a}$ & Incorporation Efficiency $(\%) \pm \mathrm{SD}^{a}$ \\
\hline MFL 1 & -1 & 1 & $88.75 \pm 1.34$ & $31.17 \pm 1.51$ \\
MFL 2 & 0 & 0 & $99.50 \pm 0.50$ & $94.48 \pm 1.17$ \\
MFL 3 & 0 & 1 & $88.53 \pm 0.42$ & $59.97 \pm 1.74$ \\
MFL 4 & -1 & -1 & $95.00 \pm 1.81$ & $91.81 \pm 0.48$ \\
MFL 5 & 1 & 0 & $89.71 \pm 0.48$ & $94.52 \pm 0.89$ \\
MFL 6 & -1 & 1 & $85.00 \pm 1.36$ & $66.33 \pm 0.72$ \\
MFL 7 & 1 & 0 & $84.67 \pm 1.17$ & $57.93 \pm 1.39$ \\
MFL 8 & 1 & -1 & $88.33 \pm 1.87$ & $82.60 \pm 0.94$ \\
MFL 9 & 0 & & $83.28 \pm 1.73$ \\
\hline
\end{tabular}

\footnotetext{
${ }^{a}$ Values represent the mean $\pm \mathrm{SD}$ of three experiments
} 
Table III. Grading for Gustatory Sensory Test

\begin{tabular}{lc}
\hline \multicolumn{1}{c}{ Parameter } & Score \\
\hline Tasteless & 0 \\
Very slightly bitter & 0.5 \\
Slightly bitter & 1.0 \\
Slight to moderate bitter & 1.5 \\
Moderately bitter & 2.0 \\
Moderate to strong bitter & 2.5 \\
Strongly bitter & 3.0 \\
Very strongly bitter & $3.0+$ \\
\hline
\end{tabular}

A and B on the dependent variables. In this design, two factors were evaluated, each at three levels, and experimental trials were performed at all nine possible combinations. A statistical model incorporating interactive and polynomial terms was used to evaluate the response (21).

$$
Y=b 0+b 1 A+b 2 A+b 11 A^{2}+b 22 B^{2}+b 12 A B
$$

where, $Y$ is the dependent variable, $b 0$ is the arithmetic mean response of the nine runs, and bi is the estimated coefficient for the factor, drug $(A)$ and polymer concentration $(B)$. The main effects $(A$ and $B)$ represent the average result of changing one factor at a time from its low to high value. The interaction terms $(A B)$ show how the response changes when two factors are simultaneously changed. The polynomial terms $\left(A^{2}\right.$ and $B^{2}$ ) are included to investigate nonlinearity.

\section{Optimization of Responses Using Desirability Function}

This technique involves a way of overcoming the difficulty of multiple, sometimes opposing responses (22). Each response is associated with its own partial desirability function. If the value of the response is optimum, its desirability equals 1 , and if it is totally unacceptable, its value is zero. Thus the desirability for each response can be calculated at a given point in the experimental domain. The optimum is the point with the highest value for the desirability.

The dissolution at $\mathrm{pH} 1.2$ was targeted to maximize in the procedure, as higher values of this is desirable. Greater dissolution at $\mathrm{pH} 1.2$ leads to greater availability of MFL in stomach. Moreover microparticles showed complete release within few min. Hence dissolution at $\mathrm{pH} 1.2$ in $15 \min \left(t_{15}\right)$ was selected. So the desirability function of this parameter was calculated by using Eq. 3 .

$$
d_{1}=\left(\frac{Y_{\mathrm{i}}-Y_{\min }}{Y_{\max }-Y_{\min }}\right)^{s}
$$

Where $d_{1}$ is individual desirability and $Y_{\mathrm{i}}$ is experimental results of dissolution at $\mathrm{pH} 1.2$. The values of $Y_{\min }$ and $Y_{\max }$ of dissolution at $\mathrm{pH} 1.2$ were 59.89 and $99.59 \%$ respectively.

To avoid grittiness of microparticles after ingestion in oral cavity, minimum particles size was desired. The observed $Y_{\min }$ and $Y_{\max }$ values of particle size were 32.08 and $236.78 \mu$, respectively. Further the problem of bitter taste of the drug, generally encountered due to dissolution of the active component in oral cavity. In addition the microparticles remain for maximum $5 \mathrm{~min}$ in oral cavity. To avoid this, minimum dissolution at $5 \mathrm{~min}$ was desired. The values of $Y_{\min }$ and $Y_{\max }$ of dissolution at $\mathrm{pH} 6.8$ in $5 \mathrm{~min}\left(t_{5}\right)$ were 2.45 and $5.25 \%$, respectively. Similarly the lowest value of bitterness score was desired for complete taste masking. Though the observed $Y_{\max }$ value of bitterness score was 3 , it was selected as 0.5 because no bitterness to very slightly bitterness was desired. The values of $Y_{\max }$ and $Y_{\min }$ of bitterness score were 0.5 and 0 , respectively. So the desirability function of particle size, drug release at $\mathrm{pH} 6.8$ and bitterness score was calculated by using following equation.

$$
d_{\mathrm{i}}=\left(\frac{Y_{\max }-Y_{\mathrm{i}}}{Y_{\max }-Y_{\min }}\right)^{s}
$$

where $d_{\mathrm{i}}$ is the individual desirability while $Y_{\mathrm{i}}$ is the experimental result. In all the experiments performed, all the experimental values were acceptable, however, the values far from the target, were little penalized, by choosing $0<\mathrm{s}<1$ (1 in this case) in Eqs. 5, 6 and 7.

$$
\begin{gathered}
d_{\mathrm{i}}=1 \text { if } Y_{\mathrm{i}}<Y_{\min } \\
d_{\mathrm{i}}=\left(\frac{Y_{\max }-Y_{\mathrm{i}}}{Y_{\max }-Y_{\min }}\right)^{s} \text { if } Y_{\min } \leq Y_{\mathrm{i}} \leq Y_{\min } \\
d_{\mathrm{i}}=0 \text { if } Y_{\mathrm{i}}>Y_{\max }
\end{gathered}
$$

\begin{tabular}{|c|c|c|c|c|c|c|c|c|}
\hline \multirow[b]{2}{*}{ Terms } & \multicolumn{2}{|c|}{ Particle Size $(\mu)$} & \multicolumn{2}{|c|}{ Drug Release at pH $1.2\left(t_{15}\right.$ in $\left.\%\right)$} & \multicolumn{2}{|c|}{ Dissolution at $\mathrm{pH} 6.8\left(t_{5}\right.$ in $\left.\%\right)$} & \multicolumn{2}{|c|}{ Bitterness Score } \\
\hline & FM & $\mathrm{RM}$ & FM & $\mathrm{RM}$ & FM & $\mathrm{RM}$ & FM & $\mathrm{RM}$ \\
\hline Intercept & 83.39 & 83.39 & 83.04 & 81.63 & 4.48 & 4.48 & 0.22 & 0.33 \\
\hline$A$ & -44.81 & -44.81 & 0.46 & 0.46 & 0.39 & 0.39 & 0.50 & 0.50 \\
\hline$B$ & 49.16 & 49.16 & 10.46 & 10.46 & -0.61 & -0.61 & -1.00 & -1.00 \\
\hline$A^{2}$ & 7.71 & - & -3.67 & - & 0.31 & 0.31 & 0.17 & - \\
\hline$B^{2}$ & -3.74 & - & 1.57 & - & -1.28 & -1.28 & 0.67 & 0.67 \\
\hline$A B$ & -48.71 & -48.71 & -8.01 & -8.01 & 0.095 & - & -0.50 & -0.50 \\
\hline
\end{tabular}

Table IV. Results of Regression Analysis

- Indicates term is omitted in reduced model, $F M$ full model, $R M$ reduced model, $t 5$ and t 15 percent drug released at 5 and 15 min, respectively 


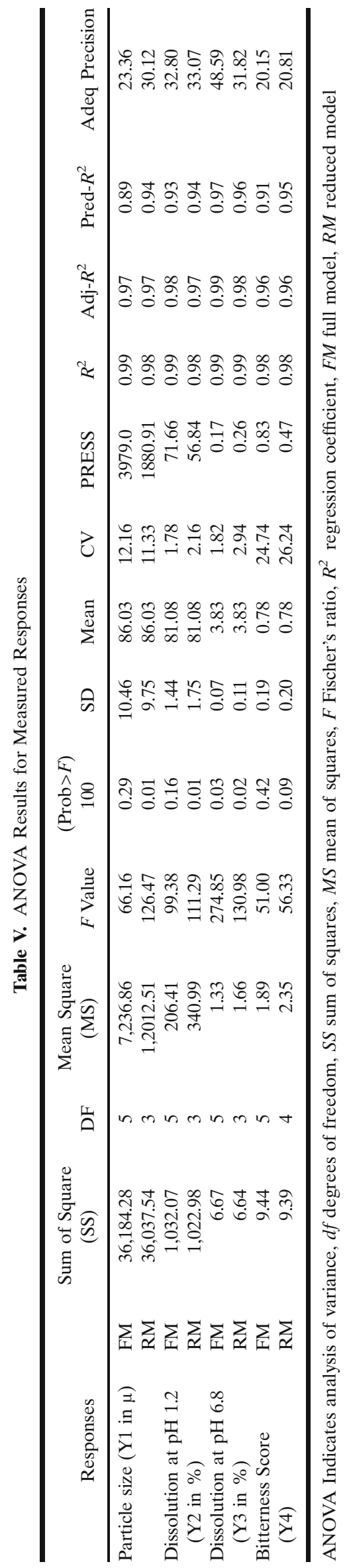

The combined desirability value was calculated from the individual values by using following equation:

$$
D=\left(d_{1} \times d_{2} \times d_{3} \times d_{4}\right)^{1 / 4}=\left(\prod_{i=1}^{4} d_{i}\right)^{1 / 4}
$$

\section{CHARACTERIZATION OF MICROPARTICLES}

\section{Determination of Incorporation Efficiency}

Microparticles containing $10 \mathrm{mg}$ MFL were weighed accurately and dissolved in methanol. Drug concentration was determined by UV spectrophotometry (Shimadzu UV visible spectrophotometer 1601) at $284 \mathrm{~nm}$. A calibration curve was used, based on standard solutions in methanol. The polymer did not interfere with the analysis at this wavelength. The percent yield and incorporation efficiency for all formulations are shown in Table II. To determine the incorporation efficiency, the following practical relationship was used:

$$
\begin{aligned}
& (\%) \text { Incorporation efficiency }=\frac{\text { Calculated drug concentration }}{\text { Theoratical drug concentration }} \\
& \times 100
\end{aligned}
$$

\section{Particle Size Analysis}

The average particle diameter and size distribution of microparticles were determined by using Malvern (Mastersizer 2000 Malvern Instruments, UK). Approximately $10 \mathrm{mg}$ of microparticles were dispersed in $2-3 \mathrm{ml}$ of filtered and degaussed phosphate buffer pH 6.8 containing $0.1 \%$ Tween 80 for 1 min using an ultrasonic bath. An aliquot of the microparticle suspension was then added into the small volume recirculation unit and circulated 3500 times/min. Each sample was measured in triplicate in the analysis. Particle size was expressed as the weighted mean of the volume distribution.

\section{Drug Release}

The in vitro drug release profile of microparticles was determined according to the paddle method described in the United State Pharmacopoeia (USP; XXIV). The in vitro drug release study was carried out in phosphate buffer $\mathrm{pH} 6.8$ because the $\mathrm{pH}$ of the saliva is in the range from 6.3 to 7.2. Further the in vitro drug release study was performed in hydrochloric acid buffer $\mathrm{pH} 1.2$ to demonstrate the availability of MFL in gastric $\mathrm{pH}$. Both the buffers of particular $\mathrm{pH}$ were prepared according to Indian Pharmacopoeia. An appropriate amount of microparticles containing $250 \mathrm{mg}$ of MFL were suspended in $900 \mathrm{~mL}$ of the buffer solution, and $3 \mathrm{~mL}$ sample was withdrawn at 1, 5, 10, 15, 30, 45 and $60 \mathrm{~min}$ and analyzed using UV spectrophotometer at $284 \mathrm{~nm}$. Each sample was replaced with fresh $3 \mathrm{ml}$ buffer solution having the same temperature. 

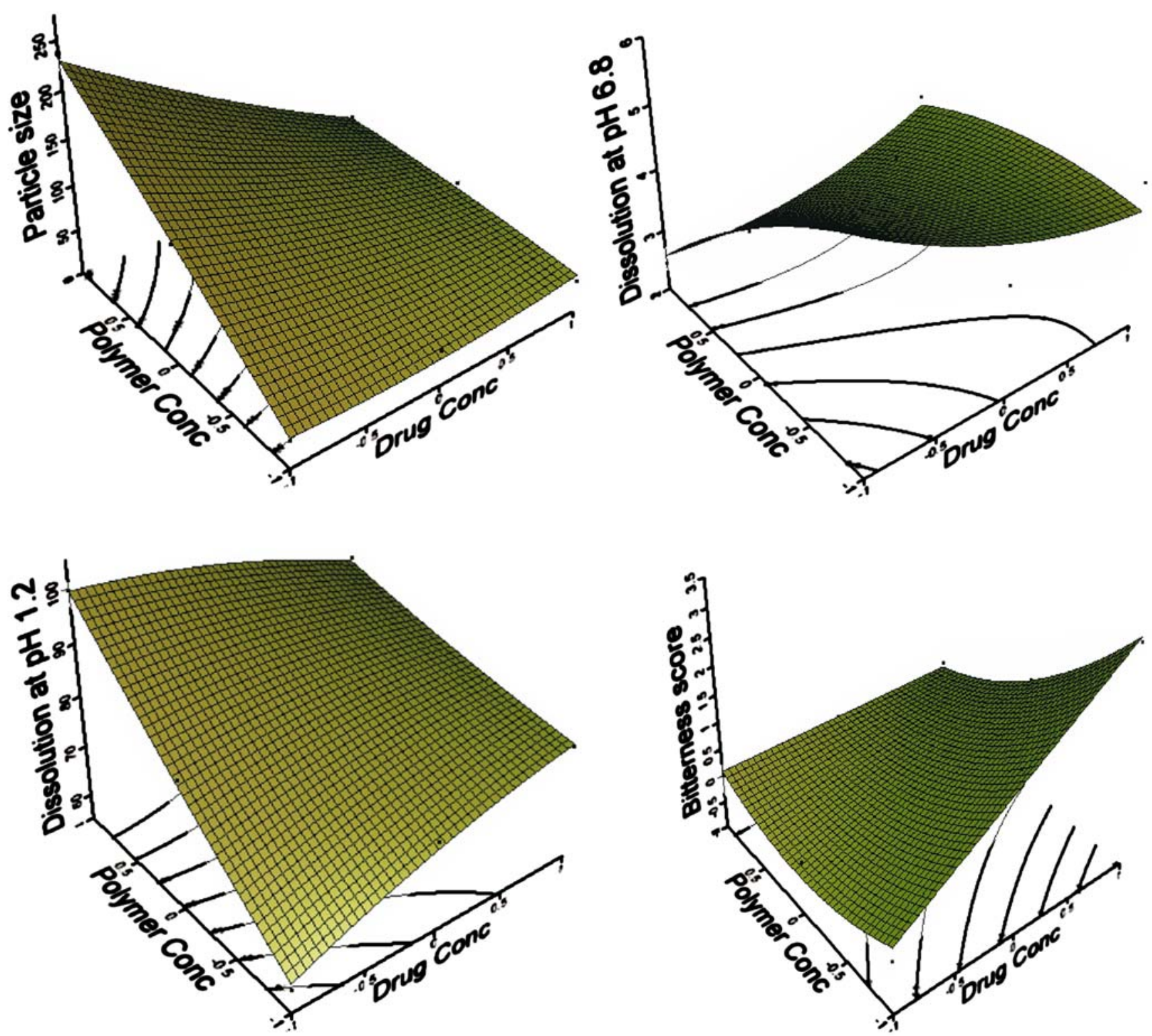

Fig. 1. Surface plots showing the effect of various formulation components

\section{Gustatory Sensation Test}

Twenty volunteers participated in sensory test. Microparticles containing $500 \mathrm{mg}$ of MFL were dispersed in $25 \mathrm{ml}$ of water for $15 \mathrm{~s}$. Immediately after preparation, each volunteer held about $1 \mathrm{ml}$ of the dispersion in the mouth for 30 s. After expectoration, bitterness was evaluated using bitterness score, classified in eight grades, corresponding to increasing bitterness and comparison of bitterness among the samples was performed on the total number of persons who selected "bitter" and "slightly bitter". The ranking scheme used is shown in Table III. The threshold of bitterness of microparticles was determined as point at which half of the volunteers described the taste as bitter or slightly bitter.

\section{Fourier Transform Infra-red Spectroscopy (FTIR)}

IR transmission spectra were obtained using a Fourier Transform Infrared spectrophotometer (FTIR-8300, Shimadzu, Japan). A total of $2 \%(w / w)$ of sample, with respect to the potassium bromide (KBr; S. D. Fine Chem Ltd., Mumbai, India) disc, was mixed with dry $\mathrm{KBr}$. The mixture was ground into a fine powder using an agate mortar before compressing into $\mathrm{KBr}$ disc under a hydraulic press at 10,000 psi. Each $\mathrm{KBr}$ 
disc was scanned 16 times at $4 \mathrm{~mm} / \mathrm{s}$ at a resolution of $2 \mathrm{~cm}^{-1}$ over a wave number region of $500-4,000 \mathrm{~cm}^{-1}$. The characteristic peaks were recorded.

\section{Differential Scanning Calorimeter (DSC)}

Differential scanning calorimetry study of pure MFL, EE and microparticles was performed using Differential Scanning Calorimeter (Mettler Toledo, DSC 822). All the samples were accurately weighed (5-8 mg), sealed in aluminium pan and heated at a scanning rate of $5{ }^{\circ} \mathrm{C} / \mathrm{min}$. Nitrogen was used as the purge gas with the flow rate set at $40 \mathrm{~mL} / \mathrm{min}$. Aluminum pans and lid were used for all samples. An empty aluminum pan was used as reference.

\section{X-ray Powder Diffractometry (XRPD)}

Vacuum grease was applied over a glass slide to stick the sample. About $100 \mathrm{mg}$ of sample was sprinkled over it to make a layer having a thickness of $\sim 0.5 \mathrm{~mm}$. All the experiments were performed on an X-ray diffractometer (Philips X'Pert MPD, Eindhoven, The Netherlands) having a sensitivity of $0.1 \mathrm{mg}$. The sample slide was placed vertically at an angle of $0^{\circ}$ in the sample chamber. An X-ray beam (Philips $\mathrm{Cu}$ target X-ray tube) of $2 \mathrm{~kW}$ was allowed to fall over the sample. As the slide moves at an angle of theta degree, a proportional detector detects diffracted X-rays at angle of $2 \theta^{\circ}$. XRD patterns were recorded using Philips JPCD software for powder diffractometry.

\section{Scanning Electron Microscopy (SEM)}

The microparticles were mounted on brass stubs using carbon paste. SEM micrographs were taken using a scanning electron microscope (JSW-5610LV, Jeol Ltd, Tokyo, Japan) at the required magnification at room temperature. a working distance of $39 \mathrm{~mm}$ was maintained, and the acceleration voltage used was $5 \mathrm{kv}$, using the secondary electron image (SEI) as the detector.

\section{RESULTS AND DISCUSSION}

MFL is extremely bitter due to presence of quinine moiety, suggesting a strong need to reduce the bitterness of MFL. Therefore, microencapsulation method was employed for reducing the bitterness of MFL in the present investigation.

\section{Experimental Design}

Preliminary investigations of the process parameters revealed that factors, drug (A) and polymer (B) concentration highly influenced the bitterness in human volunteers, particle size and dissolution at $\mathrm{pH} 1.2$ and 6.8. Hence these responses were used for further systematic studies. The dependent and independent variables were related using mathematical relationships obtained with the statistical package, DOE v6.0.5 (Stat-Ease, Inc.). The fitted polynomial equations (full and reduced model) relating the response to the transformed factors are shown in Table IV. The polynomial equations can be used to draw conclusions after 


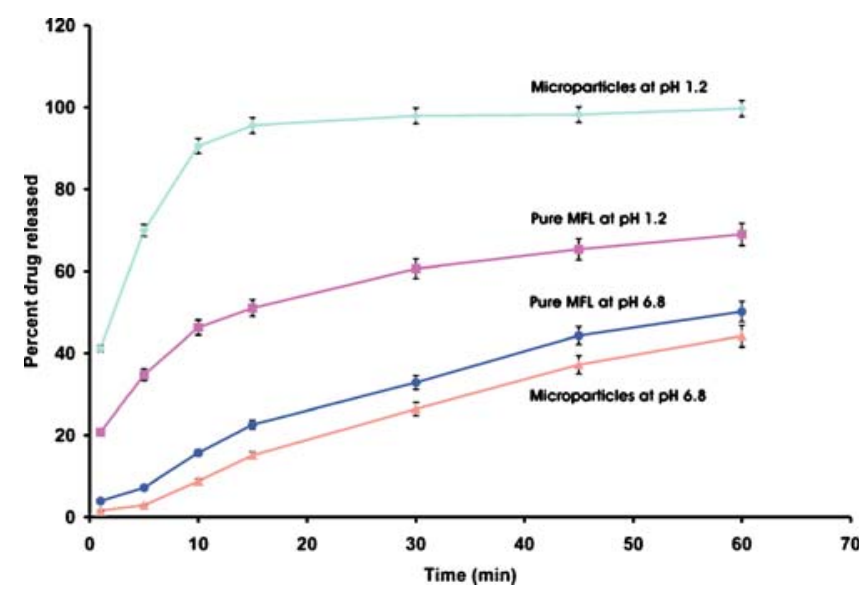

Fig. 2. Dissolution of optimized microparticles batch and MFL

considering the magnitude of coefficient and the mathematical sign it carries, i.e., positive or negative.

Table $\mathrm{V}$ shows the results of analysis of variance (ANOVA), which was performed to identify insignificant factors (23). High values of correlation coefficient $\left(R^{2}\right)$ for all dependent variables indicate a good model fit. $F$-value compares the variance with the residual (error) variance. If the variances are close, the ratio will be close to one and it is less likely that the term has a significant effect on the response. The model $F$-value implies that the model is significant for all dependent variable. Prob $>F$ is a probability seeing the observed $F$ value, if the null hypothesis is true (there is no factor effect). Smaller probability values call for rejection of the hypothesis i.e. if the Prob $>F$ value is very small (less than $0.05)$, terms in the model have a significant effect on the model. The terms having Prob $>F$ value more than 0.05 were omitted in reduced model $(24,25)$.

PRESS (predicted residual error sum of squares) indicates how well the model fits the data. The coefficients for the model were calculated without the first point. This new model was then used to estimate the first point and calculate the residual for point one. This was done for each data point and

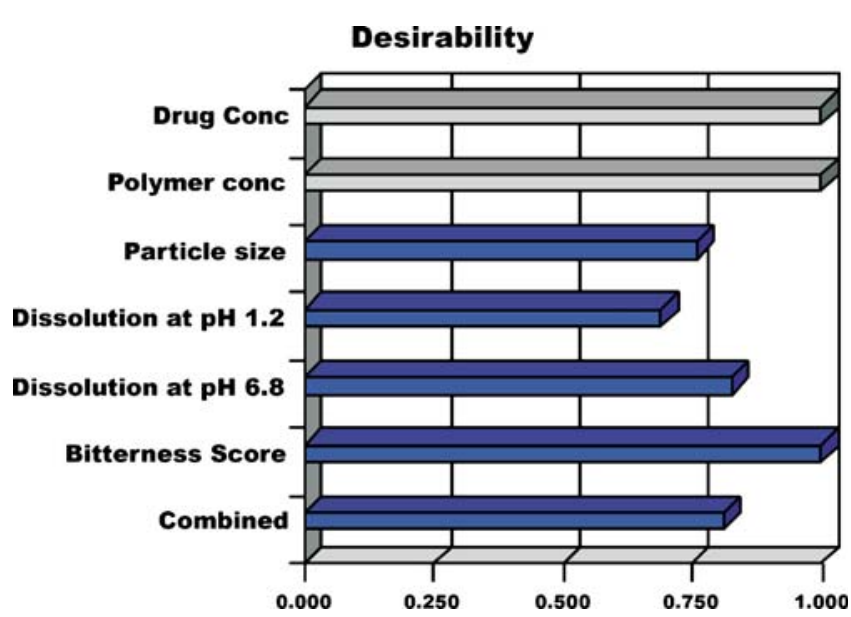

Fig. 3. Individual and combined desirability for measured responses

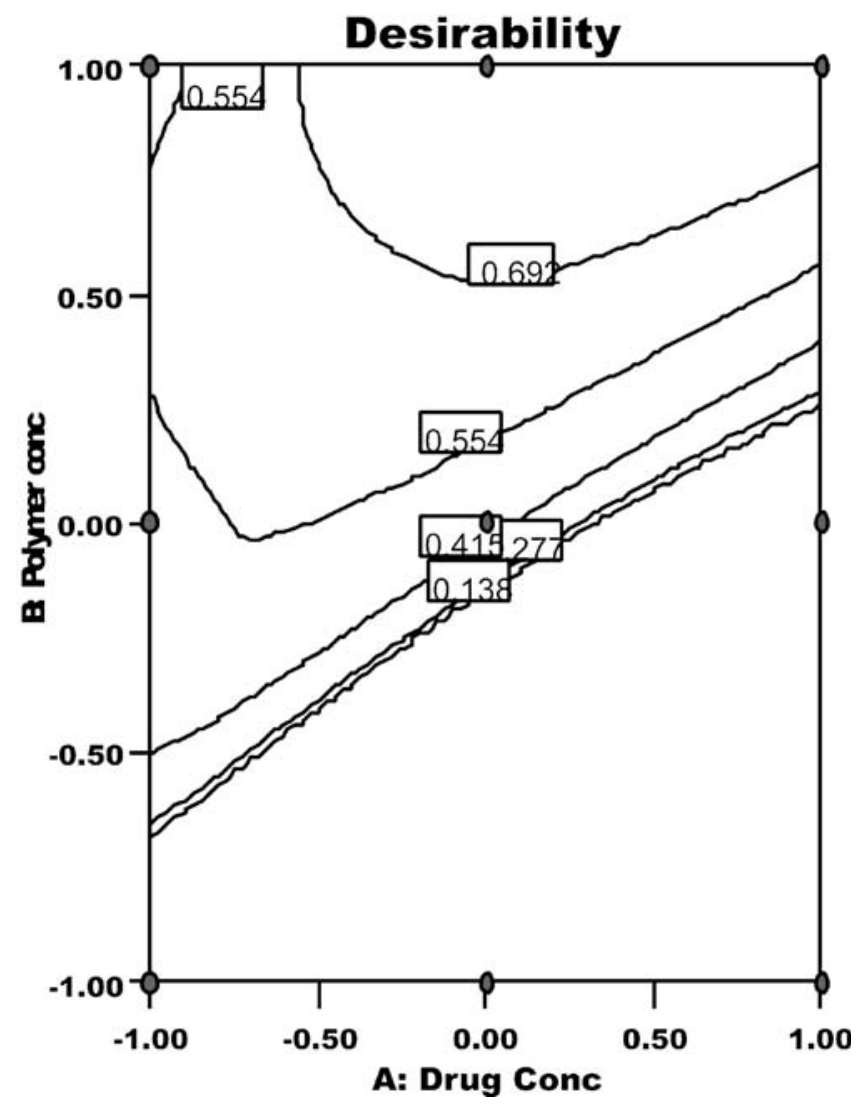

Fig. 4. Response surface of combined desirability for measured responses

the squared residuals were summed. PRESS values for all formulation shows good fit of model.

$\operatorname{Adj}-R^{2}$ measures variation around the mean explained by the model, adjusted for the number of terms in model.

$$
\operatorname{Adj} R^{2}=1-\frac{\frac{S S_{\text {residual }}}{D F_{\text {residual }}}}{\frac{S S_{\text {model }}+S S_{\text {residual }}}{D F_{\text {model }}+D F_{\text {residual }}}}
$$

Pred- $R^{2}$ measures amount of variation in new data explained by model. $\mathrm{Adj}-R^{2}$ and Pred- $R^{2}$ values are in reasonable agreement, signifying good model fit.

$$
\operatorname{Pred} R^{2}=1-\frac{\text { PRESS }}{S S_{\text {total }}-S S_{\text {block }}}
$$

Adequate precision (Adeq Precision) is a signal to noise ratio. It compares the range of predicted value at the design points to the average prediction error.

$$
\text { Adeq Precision }=\frac{p d^{2}}{n}
$$

Where $p$ is number of model parameters including intercept (b0), $d$ is residual MS from ANOVA table and $n$ is number of experiments. Both models, full model (FM) and reduced model (RM), showed Adeq precision value greater than 4 , indicating adequate model discrimination.

Multiple linear regression analysis (Table IV) revealed that $A^{2}$ and $B^{2}$ terms were insignificant for particle size and dissolution at $\mathrm{pH} 1.2$ while $\mathrm{AB}$ term was insignificant for 
dissolution at $\mathrm{pH}$ 6.8. $A^{2}$ term was insignificant for bitterness score. The surface plots are shown in Fig. 1. The theoretical (predicted) values were obtained by substituting the values of $\mathrm{A}$ and $\mathrm{B}$ in the equation. It was found that the predicted (theoretical) and experimental (observed) values were in reasonably close agreement. Table VI shows the experimental, predicted and residual values.

\section{Incorporation Efficiency}

Percent yield and incorporation efficiency were two important factors in the evaluation of the quality of the microparticles. The percent yield of most of the microparticles was always exceeded $80 \%$, while the incorporation efficiency varied for all formulations, showed in Table II. Incorporation efficiency improves with increase in polymer (26). However higher quantity of EE solution prepared in $1 \%$ acetic acid, showed solubilization of MFL. This resulted in decreased incorporation efficiency (27). This finding suggests that the present method is suitable for the preparation of microparticles of a poorly water-soluble drug, such as MFL in EE solution.

\section{Particle Size}

For particle size, drug concentration $(A)$ is negative while polymer concentration $(B)$ is positive. This indicates that on increasing EE concentration, particle size increases. It was observed that the polymer viscosity influenced particle size (26). Increasing the EE concentration have led to an increase in its viscosity and consequently a decrease in the frequency of dissociation or separation of the particles with the addition of sodium hydroxide. This results in an increase in the overall size of the microparticles.

\section{In Vitro Drug Release}

For dissolution in acidic $\mathrm{pH}$, both drug (A) and polymer (B) concentrations are positive. This indicates additive effect of MFL concentration and EE concentration. This suggests that the MFL release and solubility would be improved at acidic $\mathrm{pH}$. Release of MFL from the microparticles was completed within few minute at acidic $\mathrm{pH}$, followed by a plateau. This may be because of the high porosity of the microparticles, the hydrophilic nature of the EE, and improved wettability, provided by the dissolved EE $(17,20,28)$. Dissolution profile is shown in Fig. 2.

For dissolution at $\mathrm{pH} 6.8$, drug concentration (A) is positive while polymer concentration (B) is negative. This indicates that on increasing EE concentration, dissolution of microparticles at $\mathrm{pH} 6.8$ decreases. This finding suggests that the drug release is polymer dependent. As the concentration of EE was increased, thicker film was formed around the MFL particles, which retarded the MFL release, because of being insoluble at salivary $\mathrm{pH}(15)$. EE is expected to behave as insoluble and inert material at $\mathrm{pH} 6.8$ and showed slightly decreased release rate. This is due to the decrease in drug diffusion and/or membrane infiltration $(20,28)$. In a neutral or alkaline environment, the EE films swells, and slowly erodes and dissolves (29). However, after $15 \mathrm{~min}$ the microparticles starts swelling and releases MFL in normal way (30). 
Table VIII. Comparison of Responses Between Predicted and Experimental Values for the Cross-validation Set

\begin{tabular}{|c|c|c|c|c|c|c|}
\hline \multirow[b]{2}{*}{ Responses } & \multirow[b]{2}{*}{ Test } & \multicolumn{2}{|c|}{ Factors/coded Levels } & \multirow[b]{2}{*}{ Experimental Values $\pm \mathrm{SD}^{a}$} & \multirow[b]{2}{*}{ Predicted Values } & \multirow[b]{2}{*}{ Bias (\%) } \\
\hline & & $A$ & $B$ & & & \\
\hline \multirow[t]{2}{*}{ Particle size $(\mu)$} & 1 & 0.36 & 1 & $91.79 \pm 1.92$ & 96.42 & 4.80 \\
\hline & 2 & 0.26 & 1 & $108.20 \pm 2.11$ & 104.78 & -3.26 \\
\hline \multirow[t]{2}{*}{ Dissolution at $\mathrm{pH} 1.2\left(t_{15}\right)$} & 1 & 0.36 & 1 & $93.62 \pm 1.58$ & 91.90 & -1.87 \\
\hline & 2 & 0.26 & 1 & $94.31 \pm 1.23$ & 92.82 & -1.60 \\
\hline \multirow[t]{2}{*}{ Dissolution at $\mathrm{pH} 6.8\left(\mathrm{t}_{5}\right)$} & 1 & 0.36 & 1 & $2.57 \pm 0.79$ & 2.79 & 7.88 \\
\hline & 2 & 0.26 & 1 & $2.69 \pm 0.47$ & 2.73 & 1.46 \\
\hline \multirow[t]{2}{*}{ Bitterness Score } & 1 & 0.36 & 1 & 0 & -0.08 & -100 \\
\hline & 2 & 0.26 & 1 & 0 & -0.10 & -100 \\
\hline
\end{tabular}

$t_{15}$ Percent drug dissolved in $15 \mathrm{~min}, t_{5}$ percent drug dissolved in 5 minute, *Values represent the mean $\pm \mathrm{SD}$ of 3 experiments

\section{Gustatory Sensation Test}

For bitterness score, drug concentration (A) is positive while polymer concentration (B) is negative. This indicates that on increasing EE concentration, bitterness score of microparticles decreases. This finding is in agreement with dissolution studies carried out at $\mathrm{pH} 6.8$, because the $\mathrm{pH}$ of the saliva is in the range from 6.3 to 7.2. Further it has been reported that the MFL quinine moiety is responsible for the higher bitterness score. It has been reported that MFL produces bitterness by depolarizing taste cells by closing $\mathrm{K}^{+}$ channels (31). The microparticles are insoluble at salivary $\mathrm{pH}$ and forms physical barrier between the MFL and $\mathrm{K}^{+}$channel present in the cell membrane of taste buds. Thus reducing the bitterness score of microparticles.

\section{Optimization Using Desirability Function}

Any process can only be authenticated when optimum level of its variables (affecting the process) for microparticles of best quality characteristics is recognized. Desirability function is one excellent tool for identifying the optimum levels of variables. In this procedure, all the measured responses for independent variables which are supposed to affect the quality of the microparticles are taken into consideration. Some of these responses have to be minimized

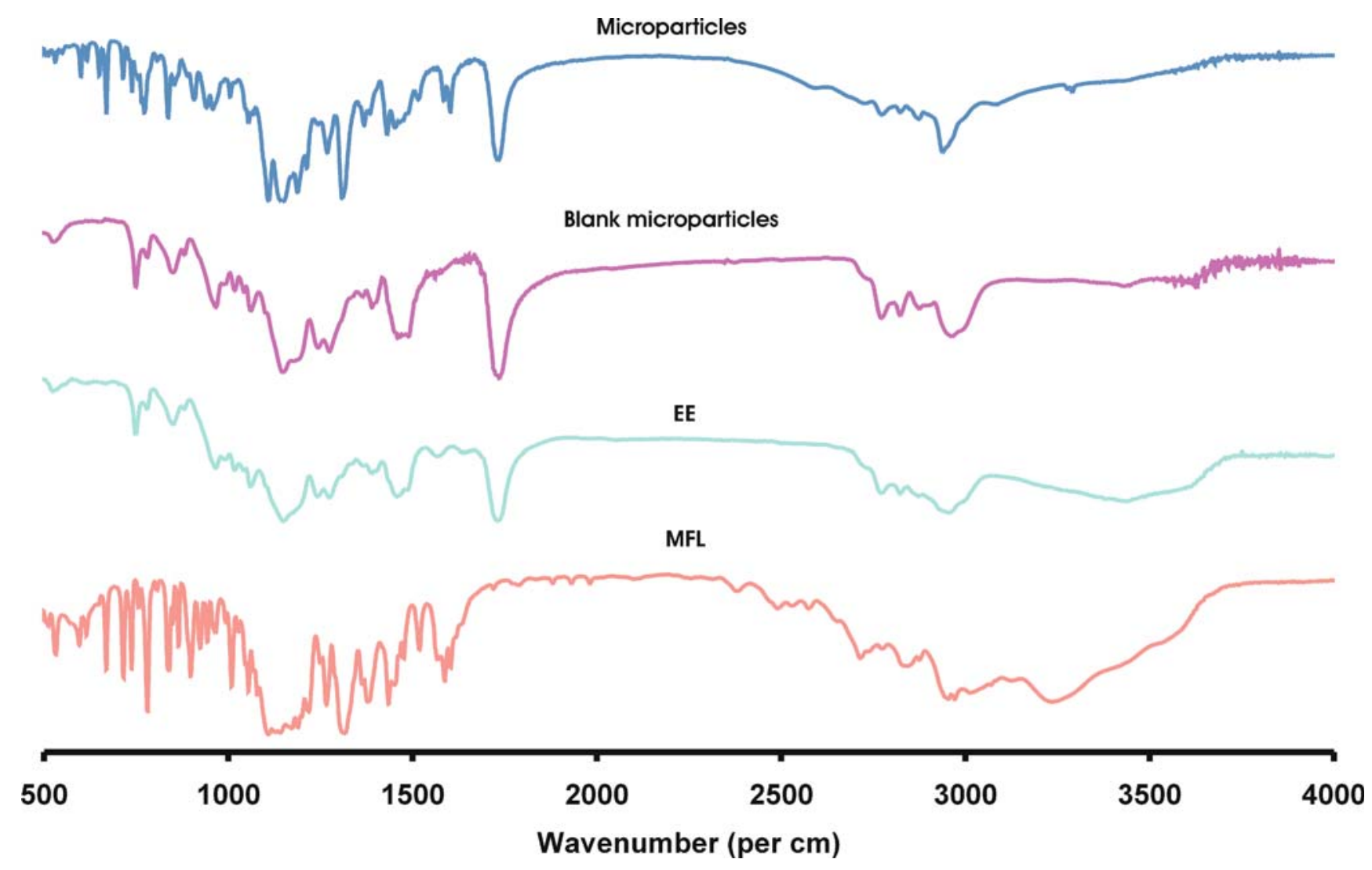

Fig. 5. FT-IR spectra of MFL, EE, blank microparticles and optimized microparticles 
and some have to be maximized, in order to pour desired characteristics in the microparticles. Using the desirability function, all the dependant variables were combined to get one combined response i.e., the overall or combined desirability. The combined desirability response was calculated from the individual desirability of each of the responses using DOE v6.0.5 (Stat-Ease, Inc.). The individual desirability of all measured responses is reported in Fig. 3. The optimized batch was identified with a combined desirability value of 0.83 (Fig. 4). Table VII enlists the optimized values for all the independent process variables and their responses.

\section{Cross Validation of the Model}

The reliability of the equation that described the influence of factors on all responses was assessed by cross validation of the model. The response data for two independent check point batches was collected (32). The experimental values and predicted values of each response are shown in Table VIII. The percent relative error between predicted values and experimental values of each response was calculated using following equation.

$$
\% \text { Bias }=\left[\frac{\mathrm{PV}-\mathrm{EV}}{\mathrm{PV}}\right] \times 100
$$

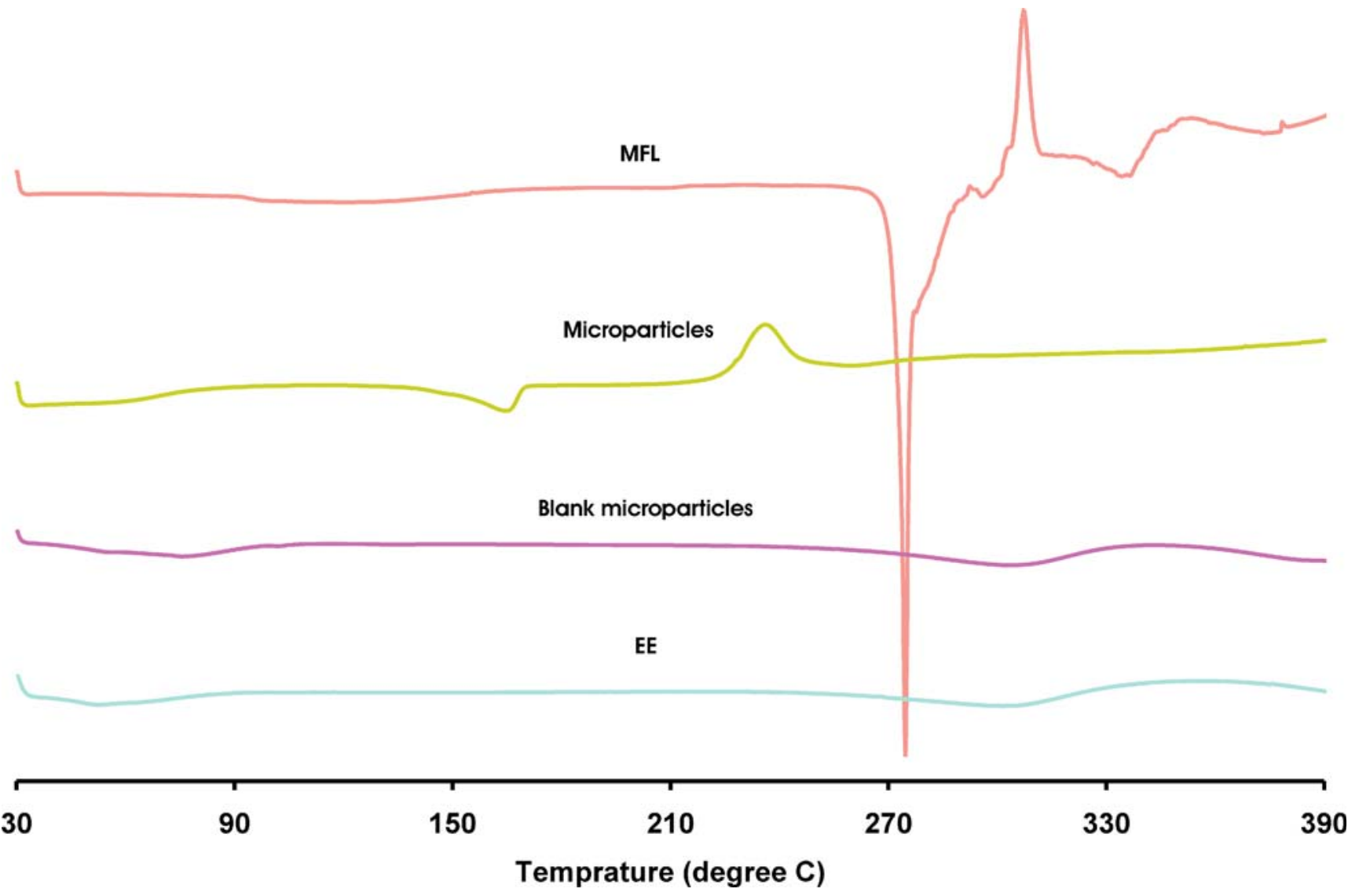

Fig. 6. DSC curve of MFL, EE, blank microparticles and optimized microparticles value. The percent bias obtained from checkpoint batches was in range of -100 to 4.80 . A low value of percent bias depicts that in all cases there was a reasonable agreement in predicted and experimental values (33).

\section{Fourier Transform Infra-red Spectroscopy (FTIR)}

The optimization batch following the acceptable limits has been further evaluated for physical characterization viz. FT-IR, DSC and XRPD. Pure MFL and EE were also run as control. The samples used for the study were prepared $48 \mathrm{~h}$ before and preserved in desiccator before use. The FT-IR spectrum of pure MFL, EE, blank microparticles and optimized microparticles are shown in Fig. 5. The characteristic peaks of MFL at $3,110 \mathrm{~cm}^{-1}$ are assigned to $\mathrm{N}-\mathrm{H}$ stretching vibration. In addition, the absorption peaks at 1,603, 1,363, 1,111, and $1,069 \mathrm{~cm}^{-1}$ can be assigned to quinine ring stretching vibration. The peak at $1,316 \mathrm{~cm}^{-1}$ can be assigned to $\mathrm{CF}_{3}$ stretching vibration. The peaks at 2,875 and $2,918 \mathrm{~cm}^{-1}$ are assigned to $\mathrm{C}-\mathrm{H}$ bridge and $\mathrm{CH}_{2}$ respectively. The peak at $1,555 \mathrm{~cm}^{-1}$ is assigned to $\mathrm{C}=\mathrm{N} / \mathrm{C}=\mathrm{C}$. The peaks at 1,288 and $1,055 \mathrm{~cm}^{-1}$ are assigned to $\mathrm{C}-\mathrm{N}$ and piperidine ring respectively. The peak at $1,174 \mathrm{~cm}^{-1}$ is due to the $\mathrm{C}-\mathrm{C} / \mathrm{N}-\mathrm{H}$ stretching vibration. The spectrum of $\mathrm{EE}$ is dominated by the carbonyl $(\mathrm{C}=\mathrm{O})$ stretching vibration at $1,735 \mathrm{~cm}^{-1}$ and the ester $\mathrm{C}-\mathrm{O}$ stretching vibrations at 1,148 and $1,188 \mathrm{~cm}^{-1}$. In addition, $\mathrm{C}-\mathrm{H}$ vibrations can be discerned at $1,389,1,450-1,490$ and $2,962 \mathrm{~cm}^{-1}$. The absorptions at 2,772 and $2,822 \mathrm{~cm}^{-1}$ can be assigned to the
Where PV is predicted value and EV is experimental 
dimethyl-amino groups. The spectrum of microparticles corresponds to the superimposition of MFL and EE with no significant shift in the major peaks. This confirms presence of MFL in microparticles.

\section{Differential Scanning Calorimeter (DSC)}

Figure 6 shows the DSC curve of pure MFL, EE, blank microparticles and optimized microparticles. The pure MFL shows an endothermic peak at $271.38{ }^{\circ} \mathrm{C}$, followed by exothermic peak at $308.36{ }^{\circ} \mathrm{C}$. The characteristic endothermic peak corresponding to melting peak of MFL was shifted towards lower temperature $\left(164.53{ }^{\circ} \mathrm{C}\right)$, with reduced intensity in the microparticles, suggesting phase transition of MFL in EE microparticles.

\section{X-ray Powder Diffractometry (XRPD)}

$X R P D$ analysis was performed to confirm the results of DSC studies. XRPD patterns of MFL, EE, blank microparticles and optimized microparticles are shown in Figure 7. In X-ray diffractogram of MFL, sharp peaks at a diffraction angle $(2 \theta)$ of $11.52^{\circ}, 14.31^{\circ}, 16.37^{\circ}, 18.03^{\circ}, 20.11^{\circ}, 21.26^{\circ}$, $23.37^{\circ}, 25.50^{\circ}, 32.57^{\circ}$ indicates the presence of crystalline drug, while microparticles shows sharp peaks at $7.88^{\circ}, 13.84^{\circ}$, $14.80^{\circ}, 16.56^{\circ}, 17.82^{\circ}, 19.57^{\circ}, 20.50^{\circ}, 22.23^{\circ}, 23.39^{\circ}$. New peaks at $7.88^{\circ}, 13.84^{\circ}, 17.82^{\circ}, 19.57^{\circ}$ and $22.23^{\circ}$ were observed in microparticles, indicating phase transition of MFL in EE microparticles.

\section{Scanning Electron Microscopy (SEM)}

Figure 8 illustrated the SEM micrographs of MFL, EE and optimized microparticles. MFL existed in needle shape whereas EE was seen as small cubes. Original morphology of both components was disappeared in microparticles. Microparticles showed encapsulation of the drug particles. Therefore the close contact between the polymer and drug might be responsible for masking the bitter taste in microparticles.

\section{CONCLUSION}

The study conclusively demonstrated complete taste masking of MFL in microparticles using EE as polymer. Present work suggests that both variables have its own significant complimentary role in enhancement of the process rather than having exclusive effect. The FTIR, DSC and XRPD studies indicated interaction of MFL, at the molecular level, in EE microparticles. The results of the experiments presented may be of value for the pharmaceutical industries dealing with bitter drugs to improve
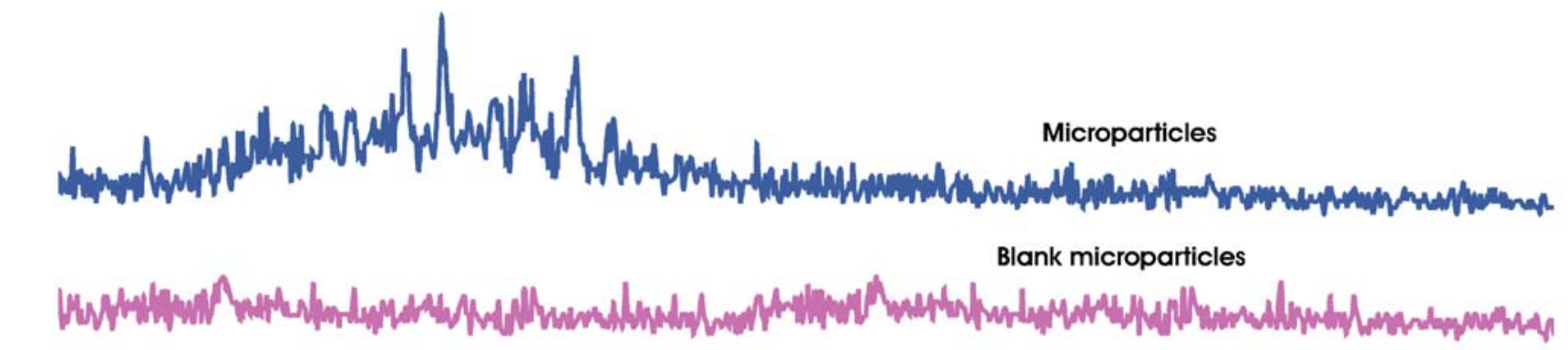

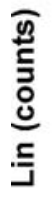
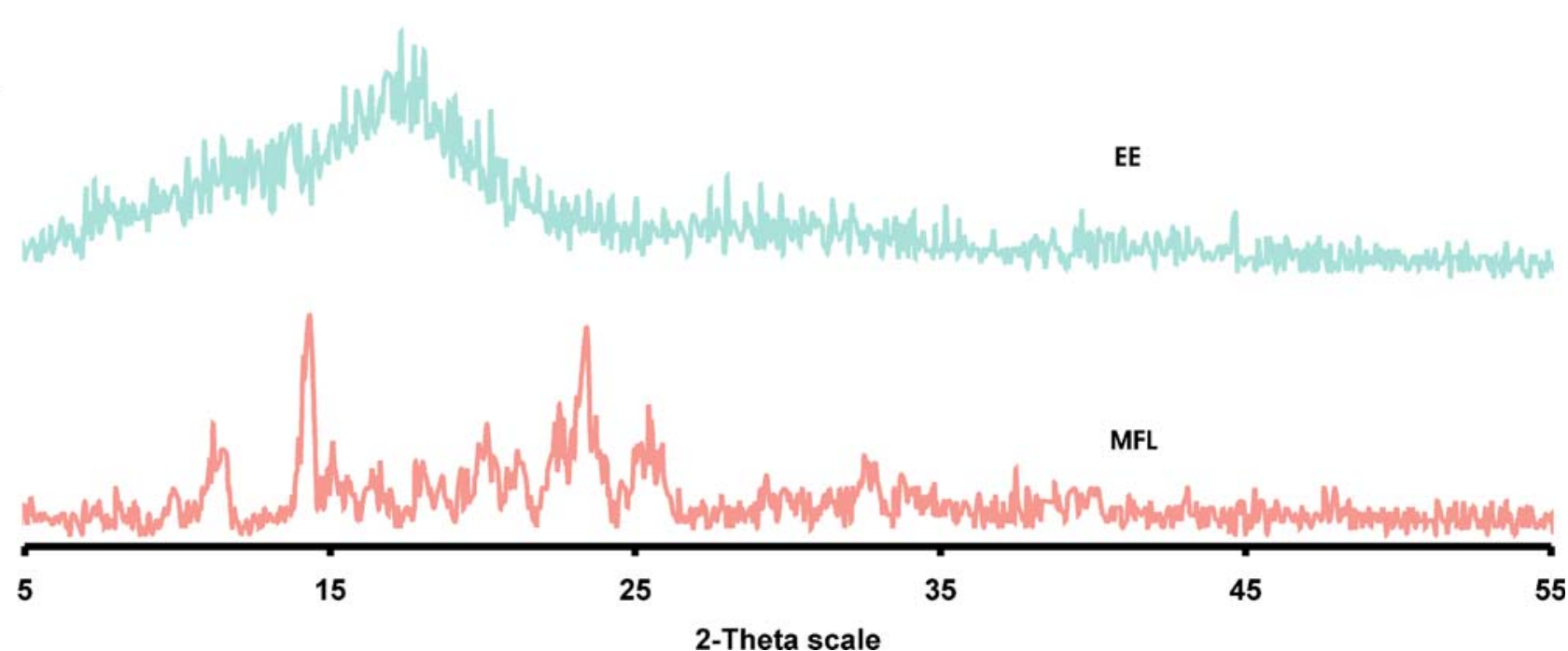

Fig. 7. XRPD patterns of MFL, EE, blank microparticles and optimized microparticles 

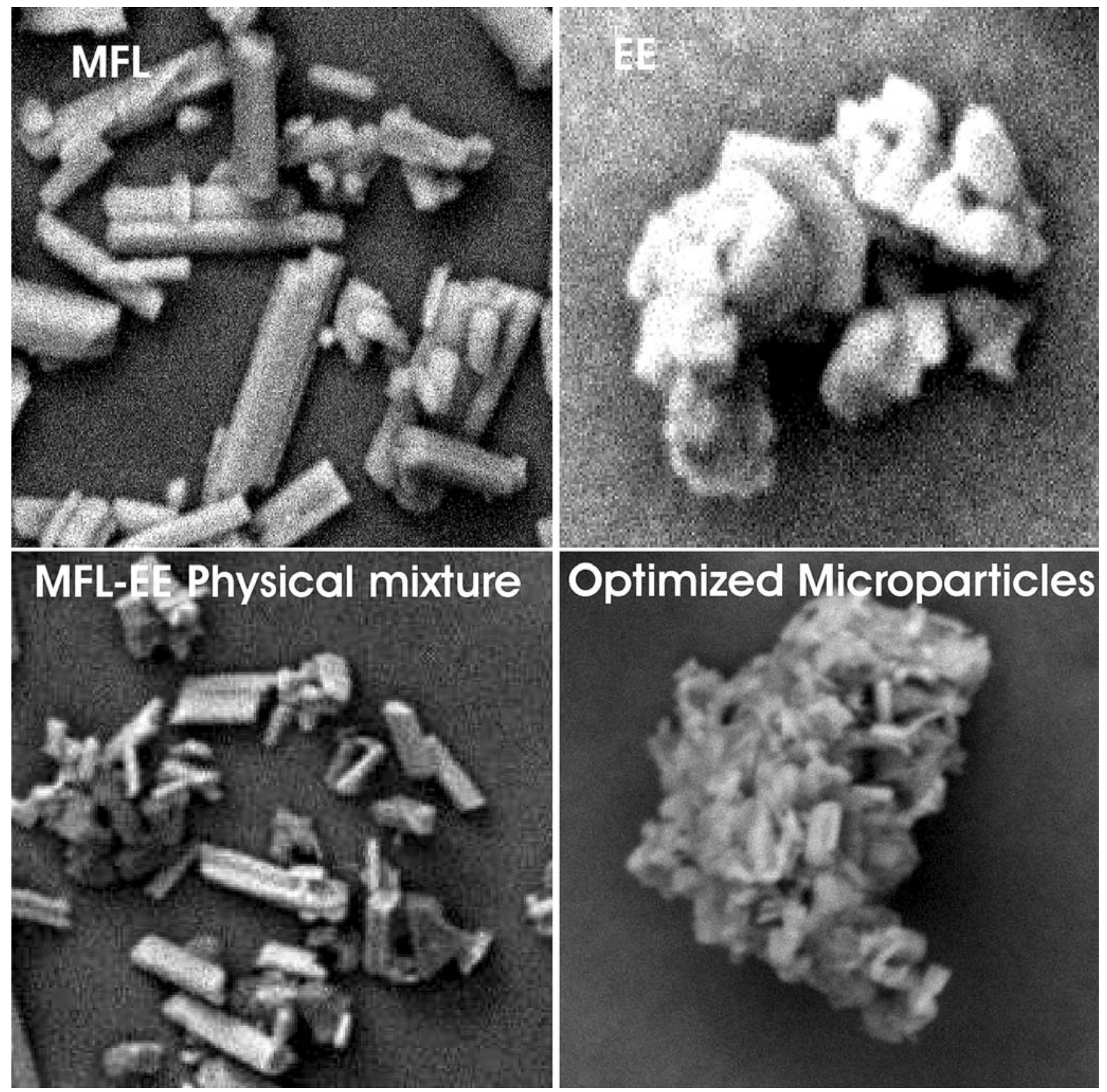

Fig. 8. SEM photographs of MFL, EE, MFL-EE physical mixture and optimized microparticles

patient compliance and thus effective pharmacotherapy. Further it is possible to mask the bitterness of single high dose $(250 \mathrm{mg})$ drugs like MFL with comparatively minimum concentration of polymer for oral formulations.

\section{ACKNOWLEDGEMENT}

The authors are thankful to Degussa India Pvt. Ltd., Mumbai for providing the polymeric material. Further the support from STIC, Cochin is greatly acknowledged.

\section{REFERENCES}

1. G. M. Roy. Taste masking in oral pharmaceuticals. Pharm. Tech. (Europe) 24-35 (1994).

2. S. Harmik, S. Yasmin, and K. K. Roop. Taste masking technologies in oral pharmaceuticals: recent developments and approaches. Drug Dev. Ind. Pharm. 30:429-448 (2004).

3. N. William. Anti-infective. In A. R. Gennaro (ed.), Remington's: The Science and Practice of Pharmacy, Vol. 2, Lippincott Williams and Wilkins, Philadelphia, PA, 1547.

4. K. Shimano, O. Kondo, A. Miwa, Y. Higashi, and S. Goto. Evaluation of uniform-sized microcapsules using a vibrationnozzle method. Drug Dev. Ind. Pharm. 21:331-347 (1995). 
5. M. Cuña, M. L. Lamosa, J. L. Vila Jato, D. Torres, and M. J. Aloso. $\mathrm{pH}$ dependent cellulosic microspheres containing cefuroxime axetil: stability and in vitro release behaviour. Drug Dev. Ind. Pharm. 23:259-265 (1997).

6. J. Barra, F. Lescure, and E. Doelker. Taste masking as a consequence of the organisation of powder mixes. Pharm. Acta Helv. 74:37-42 (1999).

7. J. Szejtli and L. Szente. Elimination of bitter, disgusting tastes of drugs and foods by cyclodextrins. Eur. J. Pharm. Biopharm. 61:115-125 (2005).

8. R. Agarwal, R. Mittal, and A. Singh. Studies of ion-exchange resin complex of chloroquine phosphate. Drug Dev. Ind. Pharm. 26:773-776 (2000).

9. M. Y. F. Lu, S. Borodkin, L. Woodward, P. Li, C. Diesner, L. Hernandez, and M. Vadnere. A polymer carrier system for taste masking of macrolide antibiotics. Pharm. Res. 8:706-712 (1991).

10. R. Chopra, G. Alderborn, J. M. Newton, and F. Podezeck. The influence of film coating on pellet properties. Pharm. Dev. Tech. 7:59-68 (2002)

11. C. M. Blase, and M. N. Shah. Aqueous pharmaceutical suspensions for pharmaceutical actives. EP Patent 0556057. Aug 18, 1993.

12. C. Appelgren and C. Eskilson. Novel method for the granulation and coating of pharmacologically active substance. Drug Dev. Ind. Pharm. 16:2345-2351 (1990).

13. R. Sjoqvist, C. Graffeer, and J. Ekamn. In vitro validation of the release rate and palatability of remoxipride-modified release suspension. Pharm. Res. 10:1020-1030 (1993).

14. Y. Hashimoto, M. Tanaka, H. Kishimoto, H. Shiozawa, K. Hasegawa, K. Matsuyama, and T. Uchida. Preparation, characterization and taste masking properties of polyvinylacetal diethylamino acetate microsphere containing trimebutine. $J$. Pharm. Pharmacol. 54:1323-1328 (2002).

15. V. R. Sinha and K. Rachna. Binders for colon specific drug delivery: an in vitro evaluation. Int. J. Pharm. 249:23-31 (2002).

16. E. Elisabetta, R. Roberta, C. Rita, C. Franco, and N. Claudio. Production of Eudragit microparticles by spray-drying technique: influence of experimental parameters on morphological and dimensional characteristics. Pharm. Dev. Tech. 5:267-278 (2000).

17. Y. Mingshi, C. Fude, Y. Bengang, Y. Jian, W. Liang, Z. Liqiang, and K. Yoshiaki. A novel pH-dependent gradient-release delivery system for nitrendipine I. Manufacturing, evaluation in vitro and bioavailability in healthy dogs. J. Control Rel. 98:219229 (2004).

18. M. Bogataj, A. Mrhar, A. Kristl, and F. Kozjek. Eudragit E microspheres containing bacampicillin: preparation by solvent removal methods. J. Microencapsul. 8:401-406 (1991).

19. M. J. Anne, B. Catherine, and K. Cynthia. Evaluation of solid dispersion particles prepared with SEDS. Int. J. Pharm. 250:385401 (2003).
20. H. Valizadeh, A. Nokhodchi, N. Qarakhani, P. Zakeri-Milani, S. Azarmi, D. Hassanzadeh, and R. Löbenberg. Physicochemical characterization of solid dispersions of indomethacin with PEG 6000, Myrj 52, lactose, sorbitol, dextrin and Eudragit E100. Drug Dev. Ind. Pharm. 30:303-317 (2004).

21. Y. Rane, R. Mashru, M. Sankalia, and J. Sankalia. Effect of hydrophilic swellable polymers on dissolution enhancement of carbamazepine solid dispersion studied using response surface methodology. AAPS PharmSciTech. 8:Article 27 (2007).

22. G. A. Lewis, D. Mathieu, and R. Phan-Tan-Luu. Pharmaceutical experimental design, Marcel Dekker, New York, 1999.

23. S. Bolton, and S. Charles. Pharmaceutical Statistics, Marcel Dekker Inc, New York, NY, 2004, pp. 249-255.

24. M. C. Gohel and M. K. Panchal. Novel use of similarity factor $\mathrm{f} 2$ and Sd for the development of diltiazem HCL modified release tablets using a 32 factorial design. Drug Dev. Ind. Pharm. 28:77-87 (2002).

25. T. J. Shah, A. F. Amin, J. R. Parikh, and R. H. Parikh. Process optimisation and characterisation of poloxamer solid dispersion of a poorly water soluble drug. AAPS PharmSciTech. 8:29 (2007).

26. P. M. Satturwar, P. M. Mandaogade, and A. K. Dorle. A novel method for preparation of Eudragit RL microcapsules. J. Microencapsul. 19:407-413 (2002).

27. K. Rama Rao, P. Senapati, and M. K. Das. Formulation and in vitro evaluation of ethyl cellulose microspheres containing zidovudine. J. Microencapsul. 22:863-876 (2005).

28. V. M. Rao, K. Engha, and Y. Qiu. Design of pH-independent controlled release matrix tablets for acidic drugs. Int. J. Pharm. 252:81-86 (2003).

29. S. L. Claudia and E. Dorothee. Basic coating polymers for the colon-specific drug delivery in inflammatory bowel disease. Drug Dev. Ind. Pharm. 26:1239-1246 (2000).

30. L. Jinhe, Y. Libo, M. F. Sheila, J. H. Tom, W. Shunsuke, K Masataka, and J. A. Fix. In vitro evaluation of dissolution behavior for a Colon-Specific Drug Delivery System (CODESä) in multi-pH media using united states pharmacopeia apparatus II and III. AAPS PharmSciTech. 3:33 (2002).

31. T. Yamamoto, T. Nagai, T. Shimura, and Y. Yasoshima. Roles of chemical mediators in taste system. Jpn. J. Pharmacol. 76:325348 (1998).

32. M. G. Sankalia, R. C. Mashru, J. M. Sankalia, and V. B. Sutariya. Physicochemical characterisation of papain entrapped in ionotropically cross-linked Kappa-Carrageenan gel beads for stability improvement using doehlert shell design. J. Pharm. Sci. 95:19942013 (2006).

33. Y. M. Rane, R. C. Mashru, M. G. Sankalia, V. B. Sutariya, and P. P. Shah. Investigation on factors affecting chitosan for dissolution enhancement of oxcarbazapine by spray dried microcrystal formulation with an experimental design approach. Drug Dev. Ind. Pharm. 33:1008-1023 (2007). 